\title{
Profiteering from the Dot-com Bubble, Sub-Prime Crisis and Asian Financial Crisis*
}

\author{
Michael McAleer \\ Econometric Institute \\ Erasmus School of Economics \\ Erasmus University Rotterdam \\ and \\ Tinbergen Institute \\ The Netherlands \\ and \\ Department of Quantitative Economics \\ Complutense University of Madrid, Spain \\ and \\ Institute of Economic Research \\ Kyoto University, Japan \\ John Suen \\ Department of Statistics \\ Chinese University of Hong Kong \\ Wing Keung Wong \\ Department of Economics \\ Hong Kong Baptist University
}

Revised: June 2013

* For financial support, the first author wishes to acknowledge the Australian Research Council, National Science Council, Taiwan, and the Japan Society for the Promotion of Science. 


\begin{abstract}
This paper explores the characteristics associated with the formation of bubbles that occurred in the Hong Kong stock market in 1997 and 2007, as well as the 2000 dot-com bubble of Nasdaq. It examines the profitability of Technical Analysis (TA) strategies generating buy and sell signals with knowing and without trading rules. The empirical results show that by applying long and short strategies during the bubble formation and short strategies after the bubble burst, it not only produces returns that are significantly greater than buy and hold strategies, but also produces greater wealth compared with TA strategies without trading rules. We conclude these bubble detection signals help investors generate greater wealth from applying appropriate long and short Moving Average (MA) strategies.
\end{abstract}

Keywords: Technical analysis, moving average, buy-and-hold strategy, dot-com bubble, Asian financial crisis, sub-prime crisis, moving linear regression, volatility.

JEL Classifications: G1, C0. 


\section{Introduction}

The past two decades have witnessed three huge bubbles and crashes with deep and long bear markets, namely the uncontrolled exuberance during the 1990s followed by the Asian Financial Crisis, the dot-com bubble at the turn of the Century, and the bubble in the run up to the 2007 peak of over 30,000, followed by the crashes and bust after the bursting of the U.S. housing bubble. Many institutional investors suffered losses, in spite of well-established tests to detect bubbles in the stock market, namely excess volatility tests, cointegration tests, duration dependence tests, and the intrinsic bubbles model.

If such well-established tests for the existence of bubbles are available, why do such bubbles occur? Why do most investors fail to avoid the bursting of bubbles by simply leaving the market early when signals, as suggested by these quantitative tests, purportedly detect the existence of a bubble. One possible explanation may be that even though investors may be fooled into buying an overpriced asset, they believe that the market is populated by greater fools who are willing to buy at an even higher price, the so-called "greater fool" theory. Mokhtar et al. (2006) suggest that such speculators know that stock prices have exceeded their fundamental value, but they still trade while thinking that the bubble will continue. Another possible explanation is that, in practice, these bubble detection techniques are too difficult and are not available to the average investor, who have no tools to detect the stock bubbles. Consequently, such investors are not able to leave early when these signals occur to avoid market crashes and bear markets, thereafter suffering huge losses.

In this paper, we develop simple bubble detection signals that can be used by investors and regulators. We do so by analyzing the 1997 stock bubble of the Hang Seng Index (HIS), 2000 dot-com bubble, and 2008 stock bubble of HSI. In sum, we identify four properties associated with the creation and bursting of bubbles, and they serve as selling signals for investors to leave the market early before the horrendous bursting of bubbles. The four properties are as follows: (1) the run-up of abnormally high returns in the formation of the bubble, (2) the deviation of stock price from one standard deviation trend line by more than $10 \%$, (3) an increase in the volatility of stock returns, and (4) the decline in stock prices below the one standard deviation trend line.

After identifying these four signals, we suggest a trading rule to profit from the 
bursting of a bubble. We assess the performance of different buy/sell rules, namely technical analysis tools from the moving average ( $M A$ ) family, including simple $M A$ rules, dual $M A$ rules, exponential $M A$ rules for the three bubbles to examine which strategies can help investors profit even during bubble formation and bursting. Our findings show that MAs perform significantly better than the buy and hold $(B H)$ strategy, even under transaction costs. In particular, we find that MA20 rule is able to generate the greatest wealth for investors.

The remainder of this paper is as follows. Section 2 provides a brief review of the literature on speculative bubbles and technical analysis. Section 3 examines the four properties associated with the building up and bursting of a bubble, with empirical results from the 97, dot-com and 07 bubbles. The methodology in constructing the figures will be discussed. Then we suggest a trading rule to profit from the bursting of bubbles. In Section 4, different buy/sell strategies, including MA(5), MA(10), MA(20), MA(30), MA(50), DMA(5,20), DMA(5,30), EMA(5), EMA(10) and EMA(20), are examined. We recommend trading strategies for investors to avoid similar crashes and to capture investment opportunities.

\section{Literature Review}

Technical analysis (TA) has a long history of identifying and moving with the trend. It goes back to the 1700s, when Japanese rice traders traded on the Dojima Rice Exchange. TA was used widely after the 1800s, with Charles Dow laying the foundation for modern technical analysis. Later it evolved into Chartism in the early 20th Century with mechanical trading rules to generate buy/sell signals. The advent of computers enabled analysts to combine fundamental economic data with price and volume data to produce new indicators.

$T A$ is applicable to stocks, indices, commodities, futures or any tradable instrument where prices are influenced by supply and demand. TA is used to analyse historical data on prices to determine future prices on the basis of trends. There are two groups of $T A$, namely trend-following indicators and counter-trend indicators. Wong et al. (2003) find that most of the counter-trend indicators do not perform well in signaling. Since the seminal work of Friedman (1953) and Fama (1970), TA as a forecasting tool has been controversial. Some literature has found that $T A$ is not useful and cannot beat buy-and-hold strategies if transaction costs are incorporated. This is probably due to the fact there are periods when prices do not trend and fluctuate randomly (Schwager, 
1995). The goal of Chartism is to identify periods of non-random major trends.

Early empirical research by Roberts (1959) and Brealey (1969) present evidence supporting the weak form of market efficiency. Alexander (1961, 1964), the first to confirm the profitability of technical trading on individual US stocks, finds that profitability disappears when trading costs are introduced. Fama and Blume (1966), Jensen and Benington (1970), Fama (1970), and Fong and Yong (2005) observe some merit in TA. Fama and Blume (1966) even find that returns could be negative under transaction costs. Their work is consistent with the efficient market hypothesis, which state that current price reflects all available information, including the past history of prices and trading volume, so that one cannot expect abnormal returns (Fama, 1970). Sweeney (1988) shows that filter rules similar to that of Fama and Blume (1966) can produce profits depending on the level of transaction costs.

Many researchers (see Fama (1965) and Neftci (1991) among others) have concluded that $T A$ is not able to predict future movements in the stock market, and that a simple buy-and-hold strategy outperforms trading rules. Isakov and Hollistein (1998) report that transaction costs eliminate technical trading profits in the Swiss stock market. They suggest conditions where large investors may profit from moving average trading rules. However, Frankel and Froot (1990) find that there was a shift from fundamentals to $T A$ in the 1980s, and that market practitioners rely on $T A$ in forecasting the market. Moreover, the prevalence of real time information services that provide detailed, comprehensive and up-to-date technical analysis information, such as Reuters and Telerate, suggests that TA is used widely.

Mills (1997) analyses the trading rules using data from the London Stock Exchange FT30 index for the period 1935-1994, and finds that the rules actually work for the most of the sample period, at least up to the 1980's. However, these findings are also contradictory, as after the 1980's the buy-and-hold strategy dominates the trading rule strategy. Chong and $\mathrm{Ng}$ (2008) reexamine the issue by using the same data set as Mills, but divide the data into three samples and review the RSI and MACD trading rules. They conclude that the RSI and MACD trading rules are able to out-perform the buy-and-hold strategy, and find that this conclusion is robust to their choice of the sample period. The returns for the trading rules are statistically significant at the 5\% level. Other research concludes that TA contains significant forecasting power, and that analysts can identify a trend that can be exploited during the sluggish adjustment of stock price to fundamental supply and demand phenomena. 
Wong et al. (2003) conclude that TA can be useful, and calculate test statistics which suggest that both $M A$ and RSI indicators pass the tests in generating significant positive returns. Ratner and Leal (1999) estimate the efficacy of using technical trading rules (10 variable length moving averages) in emerging markets of Latin America and Asia. The results demonstrate on average that superior profits after estimated trading costs can be achieved by technical trading rules over a simple buy and hold strategy only in certain countries, specifically Mexico, Taiwan and Thailand. The profitability of technical trading rules in emerging markets may be associated with the persistence of returns, or autocorrelation, in these markets. Harvey (1995a) finds that the autocorrelation in emerging markets is much higher than in developed markets. Harvey (1995b) contends that emerging market returns seem to be predictable when using international and local risk factors.

Balvers et al. (1990) find that stock returns can be predicted using national aggregate output. Campbell (1987), Campbell and Shiller (1988a, 1988b), Fama and French (1989); and Breen et al. (1990) find that stock returns can be predicted to a large degree by the PE ratio, dividend yields, business conditions and economic variables. Lo et al. (2000) find that US share prices over the period 1962-1996 are unusually recurrent. Although they do not show that the patterns are predictable enough to make sufficient profits to justify the risks, the authors conclude that this is possible. Wong et al. (2005) conclude that in the Shanghai, Hong Kong and Taiwan stock exchanges, TA outperforms a buy-and-hold strategy, and that the cumulative wealth obtained also surpasses that of the buy-and-hold strategy under transaction costs. The conclusion is that the Greater China stock markets, in general, are not efficient.

Other work by Allen and Taylor (1990) and Neftci (1991) find that simple TA has significant forecasting power. Brock et al. (1992) demonstrate that a relatively simple set of technical trading rules possesses significant forecasting power for changes in the DJIA over a long sample period. However, Ready (1997) finds that, apart from the earlier sub-period 1970-1974, MV generally underperforms the buy and hold strategy. Bessembinder and Chan (1998) find that the Brock et al. (1992) trading rules can be profitable in some Asian countries when trading costs are considered. Hudson et al. (1996) find that the Brock et al. (1992) trading rules have some ability to predict the FT30 series of returns, but that no significant gains are found after factoring in trading costs.

Kung and Wong (2009a) conduct an analysis using two popular trading rules, 
namely MA and TRB, to assess whether or not the gradual liberalization of Taiwan's securities markets has improved the efficiency of its stock market. The results show that the two rules have considerable predictive power for 1983-1990; become less predictive for 1991-1997; and cannot predict the market for 1998-2005. These results indicate that the efficiency of the Taiwan stock market has been greatly enhanced by the liberalization measures implemented over the last 20 years.

In spite of the multitude of published papers on $T A$, only a few have addressed bubbles and downturns. Wong et al. (2001) examine whether buy/sell signals generated from the E/P ratio and bond yield could help investors avoid market crashes and beat the stock market. They conclude that the trading signals from the indicator can enable investors to escape from most of the crashes and catch most of the bull runs, thereby generating significant profits. Other attempts include Fisher and Statman (2003), who find that consumer confidence are able to predict some stock returns when predicting Nasdaq and small cap stock returns. They find a negative and statistically significant relationship between the level of the expectations component of the Conference Board confidence in one month in Nasdaq and small cap stocks in the following month. However, they do not find the same relationship to be statistically significant when considering the S\&P 500 index.

In addition, Lam et al. (2007) examine whether a day's surge or plummet in stock price can serve as a market entry or exit signal. They find that the trading rules perform well in the Asian indices but not in those of Europe and the USA. In the aftermath of the Asian financial crisis, a series of reform and liberalization measures have been implemented in Singapore to upgrade its financial markets. Kung and Wong (2009b) investigate whether these measures have led to less profitability for those investors who employ technical rules for trading stocks. They find that the three trading rules consistently generate higher annual returns for 1988-1996 than those for 1999-2007. Furthermore, they generally perform better than the buy-and-hold strategy for 1988-1996, but perform no better than the buy-and-hold strategy for 1999-2007. These findings suggest that the efficiency of the Singapore stock market has been considerably enhanced by the measures implemented after the crisis.

Wong and McAleer (2009) examine the Presidential election cycle and find that stock prices fall during the first half of a Presidency, reach a trough in the second year, rise during the second half of a Presidency, and reach a peak in the third or fourth year. They also find that the Republican Party may have greater cause to engage in active policy manipulation to win re-election than their Democratic counterparts. 
This paper is similar to Wong et al. (2005) in that we use simple TA tools, including the moving regression lines, and indicators such as stock returns and volatility to signal the formation and bursting of financial bubbles in HSI during 1997, 2008 and Nasdaq during 2000. The paper also examines different technical trading rules to see which strategy is able to generate the greatest wealth for investors.

\section{Four Properties Common to the 97, dot-com and 07 Bubbles}

\section{Property 1. Accumulation of abnormally high returns}

We first consider the 97 bubble. Table 1 shows that during the 2-year period before the 4 months preceding the peak of the 97 bubble, the ratio of the number of days with positive returns to the number of days of negative returns of the HSI daily index is around 53:47. However, in the 4 months preceding the 97 peak, the ratio increases to 59:40, a significant increase in the proportion of days with positive returns. A similar pattern is seen in the dot-com bubble, with the ratio for Nasdaq daily returns increasing from 56:44 to 68:32 for the 5 months preceding the 2000 peak. A similar increase in the ratio is seen for the 07 bubble. The ratio increases from 56.7:42.1 for the period June 10, 2005 to June 11, 2007 to 58.4:37.6 for the 4 months preceding the 07 peak.

As for the size of returns, for the 97 bubble, the average daily return for HSI in the 2-year period before the 4 months preceding the 97 peak is merely $0.06 \%$, but it increases to $0.40 \%$ for the 4 months before the 97 peak. The annualized return for the same 2 -year period is just $16.7 \%$, but it increases sharply to over $118.1 \%$ for the 4 months preceding the 97 peak. For the dot-com bubble, the average daily returns for NASDAQ in the 2 years before 5 months preceding the 00 peak is about $0.11 \%$, but then it increases five times to $0.43 \%$, with the annualized return for the corresponding period increasing from $44 \%$ to about 221\% (see Table 1 for further details). For the 07 bubble, the average daily return of HSI for the 2-year period preceding 4 months before the 07 peak is merely $0.08 \%$, which then increases significantly to $0.43 \%$ for the 4 months before the 07 peak. The annualized return for the same 2-year period is merely $24.1 \%$, compared to $133.4 \%$ in the 4 months preceding the 07 peak.

These results are not particularly surprising. In order to compensate for the possibility of a bubble bursting, investors would require higher returns during a 
bubble than during normal times. These two facts constitute the first property of bubble formation, namely a significant increase in the ratio of the number of days with positive returns to the number of days with negative returns for the 4 months preceding the peak of a bubble, as well as abnormally high returns for the 4 months preceding the peak of a bubble.

\section{Property 2. Peak rises more than $10 \%$ above +1 SD trend}

We plot the time series for the three bubbles examined in this paper. In order to construct these figures, we choose a low point in the preceding dominant upward trend; that is, July 14, 1995 in Figure 1A for the 97 bubble, August 31, 1998 in Figure 1B for the dot-com bubble, and March 5, 2007 in Figure 1C for the 07 bubble. Thereafter, we obtain the prediction price for a certain day by regressing stock price at time $t$ using the data from the starting point to time $t-1$. In order to do so for each time $\mathrm{t}$, we construct the moving linear regression line.

For the 97 bubble, on $7 / 8 / 97$, the HSI reaches its peak of 16,673 , which is far beyond the +1SD prediction line by $10 \%$. As for the dot-com bubble, the rise is more pronounced, with the NASDAQ rising above the +1SD prediction line by more than $17 \%$ on $10 / 3 / 00$. A similar result is seen in the 07 case. On $30 / 10 / 07$, the HSI reaches its peak of 31,638.22, which is far above the +1SD prediction line by $11 \%$.

Hence, properly 2 of a bubble is that the peak of the index could rise beyond the $+1 \mathrm{SD}$ prediction line from the moving linear regression by $10 \%$ or more.

\section{Property 3. Increase in volatility}

The third property associated with the formation of a bubble is an increase in the volatility of stock returns, where return refers to log return. The volatility is simply the standard deviation of log returns for a specified period. During a bubble formation, prices rise beyond their fundamental value and are no longer driven by objective new information, and hence are expected to be more volatile than during normal periods. This is consistent with tests on volatility to detect systematic departure of stock prices from fundamental values.

For the 97 bubble, the volatility is around 0.01 for the 2-year period before the 4 months preceding the 97 peak, which suddenly increases to over 0.012 for the half year before the 97 peak, representing an increase of $20 \%$. A similar pattern is seen for 
the dot-com bubble, with the volatility increasing from 0.18 in the 2-year period before the 3 months preceding the 2000 peak to 0.23 in the 3 months preceding the 2000 peak. The change is more pronounced for the 07 bubble. Initially, for the 2-year period before the 4 months preceding the 07 peak, the volatility is around 0.01 . Then for the 4 months preceding the 07 peak, volatility increases by over $50 \%$ to 0.017 (see Table 2 for details).

\section{Property 4. Falling below the -1SD prediction line}

Referring to Figure 1, signaling the bursting of the 97 bubble is the index dropping below the -1SD trend line on 9/10/97. Thereafter, the HSI falls by 37\% for the 19 days after the HSI drops below the -1SD trend line. For the following year, the index drops by $53 \%$, which is a deep and long recession. For the dot-com bubble (Figure 2), the Nasdaq drops below the trend line on 11/9/00. Thereafter, the index falls from 4048 to 3075 on 12/10/00, representing a decrease of $32 \%$ in just 1 month, and the index drops by $58 \%$ for the 6 months after the index crossed the -1SD trend line. For the 07 bubble (Figure 3), the HSI drops below the trend line on 21/11/07. Subsequently, 2.5 months later, the HSI drops from 27,616 on 9/1/08 to 21,758 on 22/1/08, representing a decrease of over $20 \%$ in just 13 days. For the 1 year after the index drops below the -1SD trend line, the index drops by 59\%, which is even larger than the 97 bubble.

Having identified the patterns in stock prices associated with the formation and bursting of bubbles, in the following we suggest a trading rule to profit from bubbles, and then examine different TA strategies to investigate whether this trading rule can help investors generate greater profits than without this trading rule.

Trading rule condition: For a period of no less than 4 months:

1. The percentage of the number of days with positive returns minus the percentage of the number of days with negative returns increases by more than 7 percentage points.

2. The annualized return for the period increases over $100 \%$.

3. The Peak of the stock price rises over the $+1 \mathrm{SD}$ trend line by more than $10 \%$.

4. More than $20 \%$ increase in volatility.

If the above 4 conditions occur, then we suggest turning to $M A$ short strategies when the stock price drops below the stock price regression line, until the stock price breaks a dominant downward trend. 


\section{Technical Indicators}

Moving Average (MA) is the most commonly used trend indicator. There are many studies regarding the performance of $M A$, but the findings are not consistent. For example, Brock, et al. (1992) show that MA significantly outperforms a cash benchmark when applied to the Dow Jones Industrial Average. However, Ready (1997) finds that, apart from the earliest sub-period (1970-1974), MA generally underperforms the buy-and-hold strategy. More recently, Wong, et al. (2003) support the usefulness of the MA strategy. On the other hand, Fong and Yong (2005) examine various $M A$ rules and conclude there is no evidence of significant trading profits. In this paper, we adopt the Moving Average strategy to examine whether we can profiteer from the bubbles we studies in our paper by investigating the following $M A$ rules: simple Moving Average (MA), simple Exponential Moving Average (EMA), and Dual Moving Average (DMA). These strategies are described briefly below.

\section{Simple Moving Average}

The $n$-day simple Moving Average $(M A)$ at time $t$, denoted by $M A_{t, n}$, is given by:

$$
M A_{t, n}=\frac{1}{n} \sum_{i=t-n}^{t-1} C_{i}
$$

where $C_{i}$ is the closing price at time $i$. A moving average changes in response to the addition of a new period and the shedding of the oldest period. As the calculation continues, the $n$-day moving average increases when the closing price moves upwards as the added value is larger than the deleted value. In a simple $M A$ procedure, a buy signal is generated when the closing price rises above $M A$ and a sell signal is generated when the close falls below $M A$. As moving averages are lagging indicators, they are trend following. If a clear trend exists, this method should work adequately. However, if the market is moving sideways or if there is excessive volatility, there could be many false signals. In such cases, Bollinger Bands and the MA Channels may be better trading tools than the use of Moving Averages (Leung and Chong, 2003).

\section{Exponential Moving Average}


In order to reduce the lag effect from the 'outdated' data in simple moving averages, the exponential moving average strategy has been developed. The $n$-day Exponential Moving Average (EMA) at time $t$, denoted by $E M A_{t, n}$, is defined as:

$$
E M A_{t, n}=\alpha C_{t}+(1-\alpha) E M A_{t-1, n}
$$

with $E M A_{1, n}=C_{1}$. In equation (2), $\alpha=\frac{2}{n+1}$. In addition, the first few $E M A_{t, n}$ values will be deleted so that the initial value for $E M A_{t, n}$ will not affect $E M A_{t, n}$.

Exponential moving averages reduce the lag effect from the 'outdated' data by assigning greater weight to more recent prices. The smoothing constant $2 /(n+1)$ in formula (2) works as the weight that applies to the most recent price depending on the length of the moving average. The shorter is the exponential moving average, the greater is the weight that will be assigned to the most recent price. For example: a 10 -period exponential moving average would weight the most recent price $18.18 \%$, and a 20-period exponential moving average would weight the most recent price $9.52 \%$.

EMA will react faster to recent price changes than will a simple moving average. The EMA formula works by weighting the difference between the price in the current period and the EMA in the previous period, and then updating the result of the EMA in the previous period. The following diagram shows the formation of the buy and sell signals by the use of the $M A$ strategy (either $M A$ or $E M A$ ): 


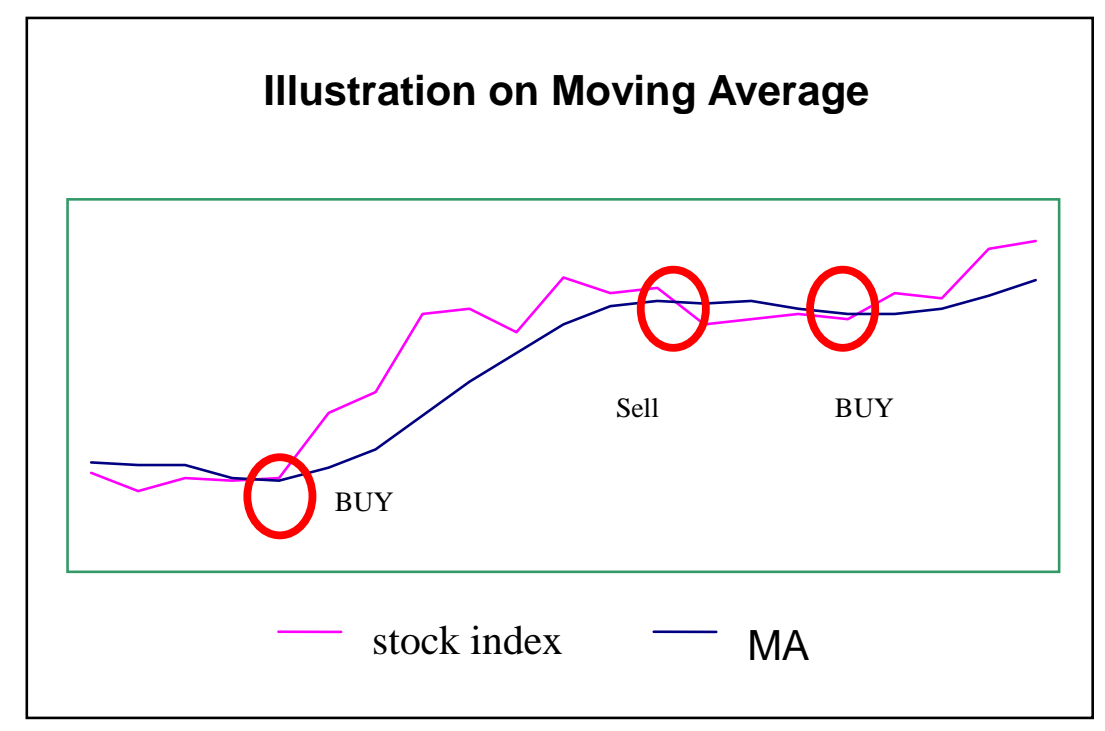

A buy signal is generated when the closing price passes the EMA from below, and a sell signal is generated when the closing price passes the EMA from above. As in the case of $M A$, the effectiveness of $E M A$ is also undermined by excessive volatilities in stock prices.

\section{Dual Moving Average}

Another commonly used trading rule (see Brock et al., 1992) is the Dual MA (DMA) strategy, denoted by $\operatorname{DMA}(n, m)$, that consists of two MAs: a 'short' $n$-day $M A$, $M A_{t, n}$, and a 'long' $m$-day $M A, M A_{t, m}$, with $m>n$. The rule generates a buy (sell) signal when the short $M A$ rises above (falls below) the long $M A$. The common DMA rules are $1-5,1-200,5-10,5-20,5-30$ and 5-200. When the DMA is formed by two $E M A s$, we call it Dual Exponential Moving Average (DEMA), denoted by $D E M A(n, m)$. As in the case of $D M A$, there are two EMAs: a 'short' $n$-day EMA, $E M A_{t, n}$, and a 'long' $m$-day EMA, $E M A_{t, m}$, with $m>n$. The rule for the DEMA signals is the same as that of the DMA. The 5-20 day and 5-30 day DMA and DEMA strategies are examined in this paper.

Unlike simple $M A$ and $E M A, D M A$ is less affected by excess volatilities on certain days due to the smoothing effect of the short $M A$. 


\section{Strategies With and Without Trading Rules}

The data used in this paper are the daily closing values of the Nasdaq and the Hang Seng Index (HSI) extracted from Yahoo.com/finance. The three periods, namely NASDAQ August 31, 1998 to September 9, 2002 , HSI July 14, 1995 to August 31, 1998, and HSI March 5, 2007 to March 31, 2009, will be used to examine different trading strategies. For each period, they will be further divided into two periods, namely before and after the bursting of bubbles, which are identified by the times when the stock price passes below the moving regression line from the peak. The six periods are NASDAQ August 31, 1998 to April 12, 2000, NASDAQ April 12, 2000 to September 9, 2002, HSI July 14, 1995 to September 1, 1997, HSI September 1, 1997 to August 31, 1998, HSI March 5, 2007 to November 15, 2007, and HSI November 15, 2007 to March 31, 2009.

Under our trading rule, we adopt the $M A$ long only strategy during bubble formation, and for the period after the stock price dropped below the stock price regression line signaling the bursting of the bubble, we will adopt the $M A$ short only strategy. In order to demonstrate the effectiveness of the proposed bubble detection signals, we will compare the above-mentioned strategy with trading rule with the $M A$ strategy without a trading rule. Without a trading rule, we will adopt the MA long and short strategy throughout the whole period.

As a strategy under the proposed trading rule, the MA short strategy is adopted when the four properties mentioned in Section 3 are satisfied, starting when the stock indexes fall below the moving linear regression lines from their peaks, until the end of the bear run. In Figure 1, for the 97 bubble, a trend line is drawn to pass through A, B and $C$, so that the end point of the bear run is around August 31, 1998. In Figure 2, for the 07 bubble, a trend line is drawn to pass through A, B and C, so that the end point is around March 31, 2009. For the dot-com bubble, as shown in Figure 3, a trend line is drawn to pass through $\mathrm{A}, \mathrm{B}$ and $\mathrm{C}$, so that the end point for the bear run is around September 9, 2002. After the end point $C$ in Figures 1, 2 and 3, the stock indexes turn bull, and the short strategy is no longer profitable.

\section{Hypothesis Testing for long strategies}

The closing prices of the indexes are used to compute the daily returns, $r_{t}$, such that 
$r_{t}=100 * \operatorname{Ln}\left(C_{t} / C_{t-1}\right)$, where $C_{t}$ is the closing price of the index on day $t$. Suppose at time $t$ there is a buy (sell) signal, and at time $t+n_{t}$ there is a sell (buy) signal, and form the long (short) trading strategy. The aggregate return $S_{t, n_{t}}$ will be given as

$$
S_{t, n_{t}}=\sum_{i=1}^{n_{t}} r_{t+i}
$$

Without loss of generality, we denote $S_{t, n_{t}}$ as $S_{t}$. Suppose we have the buy (sell) signals at $t_{1}, t_{2}, \ldots, t_{m}$, let $\Lambda=\left\{t_{1}, t_{2}, \ldots, t_{m}\right\}$, and define $\Omega$ to be the set of all these trading returns such that $\Omega=\bigcup_{i \in \Lambda} I_{i}$, where the $\left\{I_{i}\right\}$ are the disjoint sets of returns generated by the $i^{\text {th }}$ buy (sell) signals (namely, buy (sell) at time $t_{i}$ and sell (buy) at time $\left.t_{i}+n_{i}\right)$. Let $n=N(\Omega)$ be the number of elements in the set $\Omega, r_{\Omega}$ be the vector of all returns in $\Omega$, and $1_{\Omega}$ be the nx1 vector of unit elements. Assume that the mean vector and covariance matrix of $r_{\Omega}$ are $\mu_{\Omega}$ and $\Sigma_{\Omega}$, respectively.

If $\Omega$ is the set of all the daily returns generated by buy signals, let $r_{\Omega}^{\text {long }}$, $\mu_{\Omega}^{\text {long }}, \Sigma_{\Omega}^{\text {long }}$, and $n_{\text {long }}$ correspond to $r_{\Omega}, \mu_{\Omega}, \Sigma_{\Omega}$, and $n$, respectively. Similarly, if $\Omega$ is the set of all the daily returns generated by sell signals, let $r_{\Omega}^{\text {short }}, \mu_{\Omega}^{\text {short }}$, $\Sigma_{\Omega}^{\text {short }}$ and $n_{\text {short }}$ correspond to $r_{\Omega}, \mu_{\Omega}, \Sigma_{\Omega}$, and $n$, respectively. $r_{\Omega}^{\text {long }}$ is the vector of daily returns for the long strategy generated by the indicator $M A_{t}$, while $r_{\Omega}^{\text {short }}$ is the vector of daily returns for the short strategy generated by the indicator. Further define $\mu_{\text {long }}$ and $\mu_{\text {short }}$ as the population means of daily returns generated by the buy and sell signals, respectively.

The null hypothesis

$$
H_{01}: \mu_{\text {long }}=0 \text { against } H_{11}: \mu_{\text {long }}>0
$$

is used to test whether the return is profitable for the long strategy. On the other hand, the null hypothesis 


$$
H_{02}: \mu_{\text {short }}=0 \text { against } H_{12}: \mu_{\text {short }}<0
$$

is used to test whether the return is profitable for the short strategy. Statistics applied to test whether the buy and sell signals generated by the family of $M A$ yield significantly positive returns for either the long and short strategies are given by:

$$
\begin{aligned}
& T=\frac{1_{\Omega}^{T} r_{\Omega}}{\sqrt{1_{\Omega}^{T} \hat{\Sigma}_{\Omega} 1_{\Omega}}} \\
& \bar{r}=1_{\Omega}^{T} r_{\Omega} / n
\end{aligned}
$$

where $\bar{r}, r_{\Omega}$ and $\Sigma_{\Omega}$ are $\bar{r}_{\text {long }}, r_{\Omega}^{\text {long }}$ and $\Sigma_{\Omega}^{\text {long }}$ respectively if it is used to test (4) and are $\bar{r}_{\text {short }} r_{\Omega}^{\text {short }}$ and $\Sigma_{\Omega}^{\text {short }}$ respectively if it is used to test (5).

We also report the mean return difference, also known as the buy-sell spread between the long and short strategy.

The hypothesis

$H_{03}: \mu=0$ against $H_{11}: \mu>0$

Where ${ }^{\mu}$ is the mean return of using both long and short strategies.

The $t$-statistic for testing whether using both long and short strategies is profitable is

$$
T=\frac{\bar{r}_{\text {long }}-\bar{r}_{\text {short }}}{\sqrt{\sigma_{\text {long }}^{2} / n_{\text {long }}+\sigma_{\text {short }}^{2} / n_{\text {short }}}} .
$$

The test statistic $T$ will be approximately distributed as $N(0,1)$ if $\mu$ ( $\mu_{\text {long }}$ and $\mu_{\text {short }}$ ) is 0 . In estimating $\hat{\Sigma}_{\Omega}$, we set the entries to be zero if they are not significant at the $5 \%$ level.

For example, for the Taiwan stock market data for the simple MA(5) long strategy, the only significant autocorrelations are at lags 1,3 and 4, with values of $-0.078,-0.090$ and -0.073 , respectively. Thus, in testing this rule for Taiwan data, we 
set all entries to be zero except autocorrelations at lags 1,3 and 4.

Because $n$ is very large, $T$ will approach the standard normal distribution by virtue of the Central Limit Theorem. Thus, the profit generated by using the $M A_{t}$ strategy is significantly greater than zero if

$$
\begin{cases}T>\mathrm{z}_{\alpha} & \text { in a long position } \\ T<-\mathrm{z}_{\alpha} & \text { in a short position }\end{cases}
$$

where $\mathrm{z}_{\alpha}$ is the critical value such that $\alpha=P\left(Z>\mathrm{z}_{\alpha}\right)$ and $Z$ follows the standardized normal distribution.

Nonetheless, it is well known that the daily return is not i.i.d. (independent and identical distributed), and it is also not normal (see, for example, Fama, 1965; Fama and French, 1988). It is useful to refer to Lo and MacKinlay (1990) for the violation of the normality assumption, and Conrad and Kaul (1988) for the violation of the independence assumption for daily returns. In order to accommodate the possibility that the Central Limit Theorem is not effective for our data set, we use a bootstrap technique (Hall, 1992) in the empirical analysis to check for normality. The results obtained from the bootstrap approach are very close to those obtained by assuming the statistic $T$ to approach the standard normal distribution. Thus, we only report the results obtained by the latter method.

In order to check whether any of the moving average approaches significantly outperforms the $B H$ strategy, we let $\bar{r}_{B H}$ and $\mu_{B H}$ be the sample and population means of daily returns, respectively, for the $B H$ strategy, and use $\bar{r}$ and $n$ as defined in (6). Recall that $\bar{r}$ is equal to $\bar{r}_{\text {long }}$ if $\Omega$ is generated by the buy signals, and is equal to $\bar{r}_{\text {short }}$ if $\Omega$ is generated by the sell signals. Let $\mu\left(\mu_{\text {long }}\right.$ and $\left.\mu_{\text {short }}\right)$ be the mean and $\sigma^{2}\left(\sigma_{\text {long }}^{2}\right.$ and $\left.\sigma_{\text {short }}^{2}\right)$ the variance of $r_{t}$, respectively. Then we have $\sigma^{2}=1_{\Omega}^{T} \Sigma_{\Omega} 1_{\Omega} / n$, where $1_{\Omega}^{T} \Sigma_{\Omega} 1_{\Omega}$ is defined in (6). In order to check whether any of the moving average approaches significantly outperforms the $B H$ strategy, it is necessary to test whether the return, $\mu_{\text {long }}$, generated by the long strategy using the 
$M A$ family is significantly greater than the return, $\mu_{B H}$, using the $B H$ strategy.

The analysis described above is used to test the null hypothesis

$$
H_{03}: \mu_{\text {long }}=\mu_{B H} \text { against } H_{13}: \mu_{\text {long }}>\mu_{B H} .
$$

Similarly, the null hypothesis

$$
H_{04}: \mu_{\text {short }}=\mu_{B H} \text { against } H_{14}: \mu_{\text {short }}<\mu_{B H}
$$

is used to test whether the return, $\mu_{\text {short }}$, generated by the short strategy using the $M A$ family is significantly greater than the return, $\mu_{B H}$, obtained from using the $B H$ strategy. Let $R=\left(\bar{r}, \bar{r}_{B H}\right)^{T}, \quad \Sigma$ represents the variance matrix of $R$, and introduce the following test statistic to test whether a long or short strategy using the buy and sell signals generated by the $M A$ family significantly outperforms the $B H$ strategy:

$$
T^{\prime} \approx \frac{a^{T} R}{\sqrt{a^{T} \Sigma a}}
$$

where $a=(1,-1)^{T}$.

The statistic $T^{\prime}$ should approach the standard normal distribution by virtue of the Central Limit Theorem as the sample size is very large in this paper. As discussed above, in order to accommodate the possibility that the Central Limit Theorem is not effective for our data set, we use a bootstrap technique in the empirical analysis to check for normality. The results obtained from the bootstrap approach are very close to those obtained by assuming the statistic $T$ to approach the standard normal distribution. Thus, we only report the results obtained by the latter method.

The buy/sell strategy is significantly profitable if

$T>z_{\alpha} \quad$ in a long position

$T<-Z_{\alpha}$ in a short position. 
The buy/sell strategy is significantly better than the buy/hold strategy if

$T^{\prime}>z_{\alpha}$ for both long and short positions.

The statistics $T$ and $T$ ' will be applied to the aforementioned six periods for the three bubble periods.

\section{Wealth analysis}

In addition to evaluating the performance of these TA strategies, we have also created a portfolio with an initial amount of $\$ 1 \mathrm{M}$ local currency to compare the performance of different strategies. As trading costs are not negligible in buy/sell strategies, it is necessary to take them into account. The cost of trading varies across countries. For Hong Kong, investors pay a stamp duty of $0.1 \%$, as well as a small amount for commission, transaction levy, transfer fee, trading fee, and a transfer deed fee. For the USA, the trading fee normally ranges from US\$9.99 to US\$19.99. For simplicity, we will impose a transaction cost of $0.1 \%$ in both cases.

\section{Empirical Results}

First, we will describe market returns for the full three periods, namely NASDAQ 31/8/98-9/9/02, HSI 14/7/95-31/8/98, and HSI 5/3/07-31/3/09. These are the returns that investors would receive from a buy/hold strategy. Hence, the t-value could be used to test whether the buy/hold strategy could generate significant returns for the three periods.

As shown in Table 4, for all three periods, the $B H$ strategy did not generate significantly positive returns in any of the three periods and actually it gives negative returns.Hence, it is necessary to find strategies other than a buy/hold strategy to generate profits from the bull and bear runs. As will be shown below, TA strategies not only generate significantly positive returns, but they could also generate a significant amount of wealth from active buying and selling strategies.

\section{Returns analysis from TA strategies under trading rules}

Under a trading rule, a long and short strategy is adopted during a bubble formation, and a short strategy is adopted after the stock price passes through the stock price regression line from the peak. Tables 5 to 7 report the average daily returns, and the 
corresponding test statistics, $T$, under the trading rule for the 3 periods. The difference between the returns from the $T A$ and $B H$ strategies is also computed, showing the test statistics $T^{\prime}$, as well as the corresponding p-values. In addition, the total numbers of holding days $(N)$ generated by different strategies are also shown.

In Table 5, it is found that most $M A$ rules generate positive returns that are significant at the $5 \%$ level, so that we can conclude that all MA rules provide positive returns for the period HSI 14/7/95-1/9/97. The difference between the returns generated by the $M A$ rule and $B H$ strategy are all positive, with most being significant at the $5 \%$ level. Hence, we conclude that $M A$ rules outperform the $B H$ strategy for the period HSI 14/7/95-1/9/97. In Table 6, we find that the average daily returns from the MA strategy under our trading rule are all positive, and most are significant at the $5 \%$ level. Hence, we conclude that the $M A$ rules provide significantly positive returns for the period NASDAQ 31/8/98-12/4/00. Moreover, the difference between the average daily return generated by the $M A$ rules and the $B H$ strategy are all positive, and all are significant at the $10 \%$ level. Hence, we conclude that all the $M A$ rules outperform the BH strategy for the period NASDAQ 31/8/98-12/4/00.

From Table 7, all the $M A$ rules generate positive returns, and most are significant at the $10 \%$ level, so we can conclude that all the $M A$ rules generate positive returns for the period HSI 5/3/07-15/11/07. The difference between the returns from all the MA rules and $B H$ strategy are all positive, and all are significant at the $10 \%$ level, so that we conclude that all $M A$ rules outperform the $B H$ strategy for the period HSI 5/3/07-15/11/07.

\section{TA strategies without our trading rule}

In Tables 8 to10, we also report the returns from TA strategies without signaling the bubble, that is, we adopt long and short strategies throughout the three entire periods. In Table 8, during HSI 14/7/1995-31/8/98, most of the MA families were able to generate returns that are significant at the $10 \%$ level, with most being significant at the $5 \%$ level. Hence, we conclude that $M A$ families are able to generate significantly positive returns for the period HSI 14/7/95-31/8/98. However, the difference between the returns from long and short and $\mathrm{BH}$ strategies are not significant at the $10 \%$ level, so that we can conclude that long and short strategies are not able to beat the $B H$ strategy for the period HSI 14/7/95-31/8/98.

In Table 9 most the $M A$ families are not able to generate significantly positive 
returns for the period Nasdaq31/8/98-9/9/02. Moreover, the difference between the long and short and $B H$ strategies are not significant at the $10 \%$ level, so that we conclude that $M A$ families cannot beat the $B H$ strategy for Nasdaq 31/8/98-9/9/02. In Table 10, most of the $M A$ families did not generate returns that are significant at the $10 \%$ level. However, the difference between returns from the long and short and $B H$ strategies are significant at the $1 \%$ level, so that we conclude that long and short strategies are able to beat the $B H$ strategy for the sample given in HSI 5/3/07-31/3/09.

\section{Wealth analysis with and without trading rules}

In order to complete the empirical analysis, we establish a portfolio with initial amount of $\$ 1 \mathrm{M}$ in the beginning of the three periods, namely HSI $14 / 7 / 95-31 / 8 / 98$, NASDAQ 31/8/98-9/9/02, and HSI 5/3/07-31/3/09. With a trading rule, during the bull run (from the beginning to the point where the stock price dropped below the moving regression line from the peak), we adopt long and short only strategies using the MA family. Thereafter, we adopt short only strategies using the MA family. For comparison, we also establish the same portfolio for the $B H$ strategy. The results are shown in Tables 11 to 13.

In order to demonstrate the effectiveness of our bubble detection signals, we also show the wealth without a trading rule. As given in Tables 11 to 13, MA strategies with a trading rule are able to beat $M A$ strategies without a trading rule by $4 \%$ to $68 \%$.

Comparing the $M A$ strategies with and without trading rules, under a $0.1 \%$ transaction cost scenario, under our trading rule the $M A$ strategies are able to outperform the $M A$ strategies without a trading rule by $4 \%$ to $68 \%$. Hence, we conclude that our bubble detection signals are able to help investors generate greater wealth.

In Table 11, the most profitable strategies are MA5, 10, 20, DMA(5, 20) EMA5 with trading rule. From an initial amount of $\$ 1 \mathrm{M}$, the investment grew to more than $\$ 2.2 \mathrm{M}$ in just 3 years. In Table 12, the most profitable strategies are MA20, $\operatorname{DMA}(5,30)$ and EMA20, whereby a $\$ 1 \mathrm{M}$ initial investment has increased to more than $\$ 2.4 \mathrm{M}$ in just 4 years. In Table 13, the most profitable strategies are MA20, MA30, DMA(5,20), DMA $(5,30)$ and EMA20, such that an initial investment of $\$ 1 \mathrm{M}$ grew to more than $\$ 1.8 \mathrm{M}$ in just 2 years.

In Tables 11 to 13, we also report the wealth generated from TA strategies without trading rules, that is, we adopt long and sell strategies throughout the three periods. In Table 11, 
the greatest wealth of up to $2.29 \mathrm{M}$ is generated from MA(5), which is $10 \%$ smaller than the 2.52M generated from the same TA strategies under our trading rule. In Table 12, the greatest wealth up to $2.39 \mathrm{M}$ is generated from EMA(20), which is $16 \%$ below the $2.78 \mathrm{M}$ wealth generated from a trading rule and adopted short strategies after the bubble burst. In Table 13, the greatest wealth is generated from MA30, generating 2.08M, compared with 2.25M by the same $T A$ strategies under our trading rule.

In short, all MA strategies can generate significant returns, and all are able to outperform the $B H$ strategies. In all three cases, MA20 consistently produces a significant amount of wealth using long strategies during bull runs and short strategies during bear runs. Moreover, comparing the TA strategies with knowing and without trading rules, the former is able to beat the latter substantially, so that the signalling of a bubble is able to help investors generate significant wealth.

\section{Conclusion}

In summary, there are four primary properties associated with the formation and bursting of bubbles. The first three are about the formation of bubbles, and the fourth one signals the day of reckoning when the bubble bursts. For investors with a long position in the stock market, a conservative strategy that might be advised is as follows: if the first three patterns emerge, and the HSI drops below the moving regression line (by then the stock price would have dropped by more than $10 \%$ from its peak), then investors should sell their stocks to avoid market crashes as well as a deep and long bear market.

This is consonant with the idea that nobody invests in a financial bubble after it has burst. Most investors should have sold their shares when the index dropped below the -1SD trend line, by which time a market crash is highly likely, to be followed by a deep and long bear market. For aggressive investors, to generate the greatest wealth, they can adopt MA20 long and short strategies during bull runs, and MA20 short strategies after the stock price has dropped below the moving regression line from the peak, until the stock price breaks a dominant downward trend. As the analyses presented above shows, such strategies generate greater wealth than do $B H$ strategies and simple $T A$ strategies which adopted long and short strategies for the entire period.

From the above, we conclude that TA analysis is not only useful in normal times, as shown in Wong et al. (2005), but TA strategies are also useful during the formation of bubbles and market crashes. This is not surprising as the market is regarded as highly 
inefficient when bubbles form, such that the stock price no longer depends on fundamentals. By applying technical indicators, investors can ride the trends to generate greater wealth during bubble formation and subsequent crashes. 


\section{References}

Alexander, S., 1961, Price movements in speculative markets: Trends or random walks, Industrial Management Review, 2, 7-26.

Alexander, S., 1964, Price movements in speculative markets: Trends or random walks?, in Cootner, P. (Ed.), The Random Character of Stock Market Prices, vol. 2, MIT Press, Cambridge, MA.

Allen, H. and Taylor, M., 1990, Charts, noise and fundamentals in the London foreign exchange market, Economic Journal, 100, 49-59.

Balvers, R.J., Cosimano, T.F. and McDonald, B., 1990, Predicting stock returns in an efficient market, Journal of Finance, 55, 1109-1128.

Bessembinder, H. and Chan, K., 1998, Market efficiency and the returns to technical analysis, Financial Management, 27 (2), 5-17.

Box, G.P. and Jenkins, G.M., 1976, Time Series Analysis, Forecasting and Control. 2nd edition, Prentice-Hall.

Brealey, R., 1969, An introduction of Risk and Return from Common Stocks, MIT Press, Cambridge, MA.

Breen, W., Glosten, L.R. and Jagannathan, R., 1990, Predictable variations in stock index returns, Journal of Finance, 44, 1177-1189.

Brock, W., Lakonishok, J. and LeBaron, B., 1992, Simple technical trading rules and the stochastic properties of stock returns, Journal of Finance, 47, 1731-1764.

Campbell, J.Y., 1987, Stock returns and term structure, Journal of Financial Economics, 18, 373-399.

Campbell, J.Y. and Shiller, R.J., 1988a, The dividend-price ratio and expectations of future dividends and discount factors, Review of Financial Studies, 1, 195-228.

Campbell, J.Y. and Shiller, R.J., 1988b, Stock prices, earnings and expected dividends, Journal of Finance, 43, 661-676.

Chong, T.L. and Ng, W.K., 2008, Technical analysis and the London stock exchange: Testing the MACD and RSI rules using the FT30, Applied Economics Letters, 15, 2008, 1111-1114.

Conrad, J. and Kaul, G., 1988, Time-varying expected returns, Journal of Business, 61, 409-425.

Fama, E.F., 1965, The behavior of stock-market prices, Journal of Business, 38(1), 34-105.

Fama, E.F., 1970, Efficient capital markets: A review of theory and empirical work, Journal of Finance, 25, 383-417. 
Fama E.F. and Blume, M., 1966, Filter rules and stock market trading profits, Journal of Business, Supplement, 39, 226-241.

Fama, E. and French, K., 1988, Dividend yields and expected stock returns, Journal of Financial Economics, 22, 3-25.

Fama, E.F. and French, K., 1989, Business conditions and expected returns on stocks and bonds, Journal of Financial Economics, 25, 23-49.

Fisher K.L. and Statman, M., 2003, Consumer confidence and stock returns, Journal of Portfolio Management, 30(1), 115-127.

Fong, W.M. and Yong, L.H.M., 2005, Chasing trends: Recursive moving average rules and internet stocks, Journal of Empirical Finance, 12(1), 43-76.

Frankel. J. and Froot, K. 1990, The rationality of the foreign exchange rate: Chartists, Fundamentalists, and trading in the foreign exchange rate, American Economic Review, 80, 181-185.

Friedman, M., 1953, The case for flexible exchange rate, in Essays in Positive Economics, University of Chicago Press, Chicago.

Hall, P., 1992, The Bootstrap and Edgeworth Expansion, New York, Springer-Verlag.

Harvey, C., 1995a, The cross-section of volatility and autocorrelation in emerging markets, Finance Markets and Portfolio Management, 9, 12-34.

Harvey C., 1995b, Predictable risk and returns in emerging markets, Review of Financial Studies, 773-816.

Hudson, R., Dempsey, M. and Keasey, K., 1996, A note on the weak form efficiency of capital markets: The application of simple technical trading rules to UK stock prices - 1935 to 1994, Journal of Banking and Finance, 20, 1121-1132.

Isakov, D. and Hollistein, M., 1998, Application of simple technical trading rules to Swiss stock prices: Is it profitable?, Working paper, HEC, University of Geneva, Geneva.

Jensen, M.C. and Benington, G.A., 1970, Random walks and technical theories: Some additional evidence, Journal of Finance, 25, 469-482.

Kung, J.J. and Wong, W.K., 2009a, Efficiency of the Taiwan stock market, Japanese Economic Review, 60(3), 389-394.

Kung, J.J. and Wong, W.K., 2009b, Profitability of technical analysis in Singapore stock market: Before and after the Asian financial crisis, Journal of Economic Integration, 24(1), 133-150.

Lam, V.W.S., Chong, T.T.L. and Wong, W.K., 2007, Profitability of intraday and interday momentum strategies, Applied Economic Letters, 14, 1103-1108.

Leung, M.J. and Chong, T.T.L., 2003, An empirical comparison of moving average envelopes and Bollinger bands, Applied Economics Letters, 10, 339-341.

Lo, A.W., Mamaysky H. and Wang, J., 2000, Foundations of technical analysis: 
Computational algorithms, statistical inference, and empirical implementation, Journal of Finance, 55, 1705-1764.

Lo, A. and MacKinlay, C., 1990, When Are contrarian profits due to stock market overreaction?, Review of Financial Studies, 3, 175-205.

Mills, T.C., 1997, Technical analysis and the London Stock Exchange: Testing trading rules using the FT30, International Journal of Finance and Economics, 2, 319-331.

Mokhtar, S.H., Nassir A.Md., and Hassan, T., 2006, Detecting rational speculative bubbles in the Malaysian Stock Market, International Research Journal of Finance and Economics, 6, 102-115.

Neftci, S.N., 1991, Naïve trading rules in financial markets and Wiener- Kolmogorov prediction theory: A study of technical analysis, Journal of Business, 64, 549-571.

Ratner, M. and Leal, R.P.C., 1999, Tests of technical trading strategies in the emerging equity markets of Latin America and Asia, Journal of Banking and Finance, 23, 1887-1905.

Ready, M., 1997, Pitfalls from technical trading rules: Methods and results, Journal of Financial and Quantitative Analysis, 23, 285-300.

Roberts, H., 1959, Stock market patterns and financial analysis: Methodological suggestions, Journal of Finance, 1-10.

Schwager, J., 1995, Schwager on Futures: Technical Analysis, Wiley.

Sweeney, R., 1988, Some new filter rule tests: Methods and results, Journal of Financial and Quantitative Analysis, 23, 285-300.

Wong W.K., Chew, B.K. and Sikorski, D., 2001, Can P/E ratio and bond yield be used to beat stock markets?, Multinational Finance Journal, 5, 59-86.

Wong, W.K., Du, J. and Chong, T.T.L., 2005, Do the technical indicators reward Chartists? A study on the stock markets of China, Hong Kong and Taiwan, Review of Applied Economics, 1(2), 183-205.

Wong W.K., Manzur, M., and Chew, B.K., 2003, How rewarding is technical analysis? Evidence from Singapore stock market, Applied Financial Economics, 13(7), 543-551.

Wong, W.K. and McAleer, M., 2009, Mapping the Presidential election cycle in US stock markets, Mathematics and Computers in Simulation, 79(11), 3267-3277. 


\begin{tabular}{|c|c|c|c|c|}
\hline Period & $\begin{array}{l}\% \text { of positive } \\
\text { returns }\end{array}$ & $\begin{array}{c}\% \text { of negative } \\
\text { returns }\end{array}$ & $\begin{array}{c}\text { average daily } \\
\text { returns }\end{array}$ & $\begin{array}{l}\text { returns for the period } \\
\text { (annualized) }\end{array}$ \\
\hline \multicolumn{5}{|c|}{97 Bubble } \\
\hline $\begin{array}{l}\text { July 17, } 1995 \\
\text { to } \\
\text { April 29, } 1997\end{array}$ & $52.60 \%$ & $47.40 \%$ & $0.06 \%$ & $16.70 \%$ \\
\hline $\begin{array}{l}\text { April 29, } 1997 \\
\text { to } \\
\text { August 7, } \\
1997\end{array}$ & $59.40 \%$ & $40.60 \%$ & $0.40 \%$ & $118.10 \%$ \\
\hline $\begin{array}{c}\text { July 7, } 1995 \text { to } \\
\text { August 13, } \\
1998\end{array}$ & $51.10 \%$ & $48.90 \%$ & $-0.05 \%$ & $-10.40 \%$ \\
\hline \multicolumn{5}{|c|}{ dot-com bubble } \\
\hline $\begin{array}{l}\text { January 2, } \\
1997 \text { to } \\
\text { October } 19, \\
1999\end{array}$ & $56.50 \%$ & $43.50 \%$ & $0.11 \%$ & $44.40 \%$ \\
\hline $\begin{array}{l}\text { October } 19 \text {, } \\
1999 \text { to } \\
\text { March 10, } \\
2000\end{array}$ & $68.00 \%$ & $32.00 \%$ & $0.63 \%$ & $221.30 \%$ \\
\hline $\begin{array}{l}\text { August 31, } \\
1998 \text { to } \\
\text { September } \\
9,2002\end{array}$ & $53.40 \%$ & $46.60 \%$ & $0.00 \%$ & $0.30 \%$ \\
\hline \multicolumn{5}{|c|}{07 Bubble } \\
\hline $\begin{array}{l}\text { June 13, } 2005 \\
\text { to } \\
\text { June } 11,2007\end{array}$ & 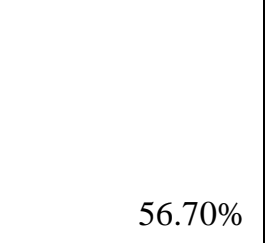 & $42.10 \%$ & $0.08 \%$ & $24.10 \%$ \\
\hline $\begin{array}{l}\text { June 11, } 2007 \\
\text { to } \\
\text { October } 30 \text {, }\end{array}$ & $58.40 \%$ & $37.60 \%$ & $0.43 \%$ & $133.40 \%$ \\
\hline
\end{tabular}




\begin{tabular}{|l|r|r|r|l|}
\hline 2007 & & & \\
\hline $\begin{array}{l}\text { June 10, 2005 } \\
\text { to March 9, } \\
2009\end{array}$ & $53.00 \%$ & $45.20 \%$ & $-0.02 \%$ & $-6.10 \%$ \\
\hline
\end{tabular}

The table shows the percentage of days with positive and negative returns, the average daily returns and returns for the period (annualized) for the periods before and during the bubble formation.

\begin{tabular}{|c|c|c|c|c|c|}
\hline \multicolumn{6}{|c|}{ Table2: Volatility of log returns } \\
\hline \multicolumn{2}{|c|}{97 bubble } & \multicolumn{2}{|c|}{ dot-com bubble } & \multicolumn{2}{|r|}{07 bubble } \\
\hline \multicolumn{2}{|r|}{ HSI } & \multicolumn{2}{|c|}{ Nasdaq } & \multicolumn{2}{|r|}{ HSI } \\
\hline Period & $\begin{array}{l}\text { Volatility of } \log \\
\text { return }\end{array}$ & Period & $\begin{array}{l}\text { Volatility of } \log \\
\text { return }\end{array}$ & Period & $\begin{array}{l}\text { Volatility of } \log \\
\text { return }\end{array}$ \\
\hline $\begin{array}{c}\text { July } 17,1995 \\
\text { to April } 29, \\
1997\end{array}$ & 0.01 & $\begin{array}{l}\text { August 31, } 1998 \\
\text { to January 4, } 2000\end{array}$ & 0.018 & $\begin{array}{c}\text { June 13, } \\
2005 \text { to } \\
\text { June 11, } \\
2007\end{array}$ & 0.009 \\
\hline $\begin{array}{c}\text { February 10, } \\
1997 \text { to } \\
\text { August 7, } \\
1997\end{array}$ & 0.012 & $\begin{array}{c}\text { January 4, } 2000 \text { to } \\
\text { March 10, } 2000\end{array}$ & 0.024 & $\begin{array}{l}\text { June 11, } \\
2007 \text { to } \\
\text { October } \\
30,2007\end{array}$ & 0.017 \\
\hline
\end{tabular}


Table 1

Stock Returns before the Bubble, and During the Bull Runs and Bear Markets of the Bubble

\begin{tabular}{|c|c|c|c|c|}
\hline Period & $\begin{array}{c}\% \text { of positive } \\
\text { returns }\end{array}$ & $\begin{array}{c}\% \text { of negative } \\
\text { returns }\end{array}$ & $\begin{array}{c}\text { average daily } \\
\text { returns }\end{array}$ & $\begin{array}{l}\text { returns for the period } \\
\text { (annualized) }\end{array}$ \\
\hline \multicolumn{5}{|c|}{97 Bubble } \\
\hline July 17,1995 to & & & & \\
\hline April 29, 1997 & $52.6 \%$ & $47.4 \%$ & $0.06 \%$ & $16.7 \%$ \\
\hline $\begin{array}{l}\text { April 29, } 1997 \text { to } \\
\text { August 7, } 1997\end{array}$ & $59.4 \%$ & $40.6 \%$ & $0.40 \%$ & $118.1 \%$ \\
\hline $\begin{array}{l}\text { July 7, } 1995 \text { to } \\
\text { August 13, } 1998\end{array}$ & $51.1 \%$ & $48.9 \%$ & $-0.05 \%$ & $-10.4 \%$ \\
\hline \multicolumn{5}{|c|}{ Dot-com bubble } \\
\hline $\begin{array}{l}\text { January 2, } 1997 \text { to } \\
\text { October 19, } 1999\end{array}$ & $56.5 \%$ & $43.5 \%$ & $0.11 \%$ & $44.4 \%$ \\
\hline $\begin{array}{l}\text { October 19, } 1999 \\
\text { to } \\
\text { March 10, } 2000\end{array}$ & $68.0 \%$ & $32.0 \%$ & $0.63 \%$ & $221.3 \%$ \\
\hline $\begin{array}{l}\text { August 31, } 1998 \\
\text { to } \\
\text { September 9,2002 }\end{array}$ & $253.4 \%$ & $46.6 \%$ & $0.00 \%$ & $0.3 \%$ \\
\hline \multicolumn{5}{|c|}{07 Bubble } \\
\hline $\begin{array}{l}\text { June 13, } 2005 \text { to } \\
\text { June 11, } 2007\end{array}$ & $56.7 \%$ & $42.1 \%$ & $0.08 \%$ & $24.1 \%$ \\
\hline $\begin{array}{l}\text { June } 11,2007 \text { to } \\
\text { October } 30,2007\end{array}$ & $58.4 \%$ & $37.6 \%$ & $0.43 \%$ & $133.4 \%$ \\
\hline $\begin{array}{l}\text { June 10, } 2005 \text { to } \\
\text { March 9, } 2009\end{array}$ & $53.0 \%$ & $45.2 \%$ & $-0.02 \%$ & $-6.1 \%$ \\
\hline
\end{tabular}

The table shows the percentage of days with positive and negative returns, the average daily returns and returns for the period (annualized) for the periods before and during the bubble formation. 
Table 2

Volatility of $\log$ returns

\begin{tabular}{|c|c|c|c|c|c|}
\hline \multicolumn{2}{|c|}{97 bubble } & \multicolumn{2}{|c|}{ dot-com bubble } & \multicolumn{2}{|c|}{07 bubble } \\
\hline \multicolumn{2}{|c|}{ HSI } & \multicolumn{2}{|c|}{ Nasdaq } & \multicolumn{2}{|l|}{ HSI } \\
\hline Period & \begin{tabular}{ll|} 
Volatility & of \\
log return &
\end{tabular} & Period & $\begin{array}{l}\text { Volatility of } \\
\text { log return }\end{array}$ & Period & $\begin{array}{l}\text { Volatility of } \\
\text { log return }\end{array}$ \\
\hline $\begin{array}{l}\text { July 17, } 1995 \\
\text { to } \\
\text { April 29, } 1997\end{array}$ & 0.01 & $\begin{array}{l}\text { August 31, } 1998 \\
\text { to } \\
\text { January 4, } 2000\end{array}$ & 0.018 & $\begin{array}{l}\text { June 13, } 2005 \\
\text { to } \\
\text { June 11, } 2007\end{array}$ & 0.009 \\
\hline $\begin{array}{l}\text { February 10, } 1997 \\
\text { to } \\
\text { August } 7,1997\end{array}$ & 0.012 & $\begin{array}{l}\text { January 4, } 2000 \\
\text { to } \\
\text { March 10, } 2000\end{array}$ & 0.024 & $\mid \begin{array}{l}\text { June } 11,2007 \\
\text { to } \\
\text { October } 30,2007\end{array}$ & 0.017 \\
\hline
\end{tabular}

The table shows the volatility of stock returns before and during the bubble formation. 
Table 3

Summary Statistics of Returns

\begin{tabular}{|l|l|l|l|}
\hline Statistic & 77 bubble (HSI) & dot-com bubble & 07 bubble \\
\hline Period & $1995-1998$ & $1998-2002$ & $2007-2009$ \\
\hline $\mathrm{N}$ & 764 & 1010 & 764 \\
\hline Mean & 0.0005 & 0.0001 & 0.001 \\
\hline Median & 0.0004 & 0.0015 & 0 \\
\hline Maximum & 0.17 & 0.13 & 0.13 \\
\hline Minimum & 0.15 & 0.1 & 0.14 \\
\hline Var & 0.0004 & 0.0006 & 0.0007 \\
\hline Skewness & 0.21445 & 0.14773 & 0.1523 \\
\hline Kurtosis & 15.45 & 1.49 & 4.63 \\
\hline Jarque-Bera test & 4940.102158 & 99.62794074 & 87.53151693 \\
\hline Runs test & $0.0001^{* * *}$ & 0.592 & $0.0001^{* * *}$ \\
\hline & & & \\
Ljung-Box-Pierce & & 0.042 & 0.25 \\
\hline Q statistics Q(12) & 0.165 & & \\
\hline
\end{tabular}

${ }^{* * *} \mathrm{p}<1 \%, * * \mathrm{p}<5 \%, * \mathrm{p}<10 \%$. 
Table 4

Returns from BH Strategy

\begin{tabular}{|l|l|l|l|l|l|l|}
\hline Index & Period & $\mathrm{n}$ & Mean (R(bh)) & Var & t & $\mathrm{p}$-value \\
\hline HSI & $1995-1998$ & 764 & $-0.05 \%$ & $0.04 \%$ & -0.68 & 0.25 \\
\hline Nasdaq & $1998-2002$ & 1010 & $-0.01 \%$ & $0.06 \%$ & -0.18 & 0.43 \\
\hline HSI & $2007-2009$ & 764 & $-0.10 \%$ & $0.07 \%$ & -1.04 & 0.15 \\
\hline
\end{tabular}

BH strategies give negative returns for all three periods.

$\mathrm{N}$ denotes the number of days during each period.

$\mathrm{T}$ is the standard $\mathrm{t}$ statistic of whether the mean returns from the buy/hold strategy is significantly different from zero. 
Table 5

HSI 1995-1998 Testing Daily Returns of the TA Strategy (under trading rule)

\begin{tabular}{|c|c|c|c|c|c|c|c|}
\hline Rule & N & $\mathrm{R}$ & $\mathrm{T}$ & $\mathrm{p}$-value & R-R(bh) & $\mathrm{T}^{\prime}$ & p-value \\
\hline MA(5) & 655 & $0.25 \%$ & 3.15 & $0.001^{* * *}$ & $0.30 \%$ & 2.78 & $0.003^{* * *}$ \\
\hline MA(10) & 663 & $0.18 \%$ & 2.36 & $0.009 * * *$ & $0.23 \%$ & 2.19 & $0.014^{* *}$ \\
\hline MA(20) & 652 & $0.19 \%$ & 2.41 & $0.008 * * *$ & $0.24 \%$ & 2.23 & $0.013 * *$ \\
\hline MA(30) & 654 & $0.12 \%$ & 1.54 & $0.062 *$ & $0.17 \%$ & 1.60 & $0.055 *$ \\
\hline MA(50) & 628 & $0.14 \%$ & 1.76 & $0.039 * *$ & $0.19 \%$ & 1.76 & $0.039 * *$ \\
\hline $\operatorname{DMA}(5,20)$ & 648 & $0.18 \%$ & 2.28 & $0.011 * *$ & $0.23 \%$ & 2.14 & $0.016^{* *}$ \\
\hline $\operatorname{DMA}(5,30)$ & 652 & $0.10 \%$ & 1.28 & $0.100 *$ & $0.15 \%$ & 1.41 & $0.080 *$ \\
\hline EMA(5) & 660 & $0.22 \%$ & 2.83 & $0.002 * * *$ & $0.27 \%$ & 2.54 & $0.006 * * *$ \\
\hline EMA(10) & 672 & $0.18 \%$ & 2.35 & $0.010 *$ & $0.23 \%$ & 2.18 & $0.015^{* *}$ \\
\hline EMA(20) & 656 & $0.17 \%$ & 2.14 & 0.016 & $0.22 \%$ & 2.04 & $0.021 * *$ \\
\hline
\end{tabular}

$* * * \mathbf{p}<0.01, * * \mathbf{p}<0.05, * \mathbf{p}<0.10$ 
Table 6

Nasdaq 1998-2002 Testing Daily Returns of the TA Strategy (under trading rule)

\begin{tabular}{|c|c|c|c|c|c|c|c|}
\hline Rule & $\mathrm{N}$ & $\mathrm{R}$ & $\mathrm{T}$ & p-value & R-R(bh) & $\mathrm{T}^{\prime}$ & p-value \\
\hline MA(5) & 728 & $0.15 \%$ & 1.68 & $0.046^{* *}$ & $0.17 \%$ & 1.40 & $0.081^{*}$ \\
\hline MA(10) & 765 & $0.15 \%$ & 1.66 & $0.048 * *$ & $0.16 \%$ & 1.37 & $0.085 *$ \\
\hline MA(20) & 758 & $0.19 \%$ & 2.12 & $0.017 * *$ & $0.20 \%$ & 1.72 & $0.042 * *$ \\
\hline MA(30) & 770 & $0.19 \%$ & 2.12 & $0.017 * *$ & $0.20 \%$ & 1.71 & $0.043 * *$ \\
\hline $\mathrm{MA}(50)$ & 723 & $0.16 \%$ & 1.71 & $0.044 * *$ & $0.17 \%$ & 1.42 & $0.078 *$ \\
\hline $\operatorname{DMA}(5,20)$ & 757 & $0.13 \%$ & 1.45 & $0.074 *$ & $0.14 \%$ & 1.21 & 0.113 \\
\hline $\operatorname{DMA}(5,30)$ & 765 & $0.20 \%$ & 2.22 & $0.013 * *$ & $0.21 \%$ & 1.79 & $0.037 * *$ \\
\hline EMA(5) & 736 & $0.15 \%$ & 1.62 & $0.052 *$ & $0.16 \%$ & 1.35 & $0.088 *$ \\
\hline EMA(10) & 745 & $0.19 \%$ & 2.11 & $0.018 * *$ & $0.20 \%$ & 1.72 & $0.043 * *$ \\
\hline $\operatorname{EMA(20)~}$ & 771 & $0.21 \%$ & 2.38 & $0.009 * * *$ & $0.22 \%$ & 1.91 & $0.028 * *$ \\
\hline
\end{tabular}

$* * * \mathrm{p}<1 \%, * * \mathrm{p}<5 \%, * \mathrm{p}<10 \%$ 
Table 7

HSI 2007-2009 Testing Daily Returns of the TA Strategy

\begin{tabular}{|c|c|c|c|c|c|c|c|}
\hline Rule & N & $\mathrm{R}$ & $\mathrm{T}$ & p-value & R-R(bh) & $\mathrm{T}^{\prime}$ & p-value \\
\hline MA(5) & 363 & $0.16 \%$ & 1.17 & 0.122 & $0.26 \%$ & 1.55 & $0.061^{*}$ \\
\hline & & & & 0.051 & & & 0.027 \\
\hline MA(10) & 367 & $0.23 \%$ & 1.64 & & $0.32 \%$ & 1.93 & $* *$ \\
\hline & & & & & & & 0.026 \\
\hline MA(20) & 372 & $0.23 \%$ & 1.65 & $0.050 * *$ & $0.32 \%$ & 1.94 & *** \\
\hline & & & & 0.014 & & & 0.008 \\
\hline MA(30) & 363 & $0.31 \%$ & 2.20 & & $0.40 \%$ & 2.40 & *** \\
\hline & & & & 0.036 & & & 0.020 \\
\hline MA(50) & 375 & $0.25 \%$ & 1.80 & ** & $0.34 \%$ & 2.06 & $* *$ \\
\hline $\operatorname{DMA}(5,2$ & & & & 0.037 & & & 0.020 \\
\hline 0) & 371 & $0.24 \%$ & 1.78 & & $0.34 \%$ & 2.05 & $* *$ \\
\hline DMA $(5,3$ & & & & 0.036 & & & 0.019 \\
\hline 0) & 358 & $0.25 \%$ & 1.80 & & $0.35 \%$ & 2.07 & $* *$ \\
\hline & & & & 0.070 & & & 0.036 \\
\hline EMA(5) & 368 & $0.20 \%$ & 1.48 & $* *$ & $0.30 \%$ & 1.80 & $* *$ \\
\hline & & & & 0.059 & & & 0.031 \\
\hline $\operatorname{EMA}(10)$ & 381 & $0.21 \%$ & 1.56 & & $0.31 \%$ & 1.87 & $* *$ \\
\hline & & & & 0.041 & & & 0.022 \\
\hline $\operatorname{EMA}(20)$ & 408 & $0.23 \%$ & 1.74 & & $0.33 \%$ & 2.01 & $* *$ \\
\hline
\end{tabular}

${ }^{* * *} \mathrm{p}<1 \%, * * \mathrm{p}<5 \%, * \mathrm{p}<10 \%$. 
Table 8

HSI July 14, 1995 to August 31, 1998

\begin{tabular}{|c|c|c|c|c|c|c|c|}
\hline \multirow[t]{2}{*}{ Rule } & \multicolumn{7}{|c|}{ Long \& short } \\
\hline & $\mathrm{N}$ & R(long \& short) & $\mathrm{T}$ & p-value & R(long \& short)-R(bh) & $\mathrm{T}^{\prime}$ & p-value \\
\hline MA(5) & 754 & $0.20 \%$ & 2.75 & $0.003 * * *$ & $0.25 \%$ & 2.43 & $0.008 * * *$ \\
\hline MA(10) & 754 & $0.14 \%$ & 1.92 & $0.027 * *$ & $0.10 \%$ & 0.97 & 0.165 \\
\hline MA(20) & 732 & $0.14 \%$ & 1.89 & $0.029 * *$ & $0.10 \%$ & 0.97 & 0.167 \\
\hline MA(30) & 729 & $0.07 \%$ & 0.95 & 0.172 & $0.03 \%$ & 0.29 & 0.386 \\
\hline $\operatorname{MA}(50)$ & 682 & $0.11 \%$ & 1.44 & $0.075 *$ & $0.07 \%$ & 0.66 & 0.253 \\
\hline $\operatorname{DMA}(5,20)$ & 731 & $0.14 \%$ & 1.89 & $0.029 * *$ & $0.10 \%$ & 0.97 & 0.167 \\
\hline $\operatorname{DMA}(5,30)$ & 727 & $0.06 \%$ & 0.81 & 0.209 & $0.02 \%$ & 0.19 & 0.423 \\
\hline EMA(5) & 753 & $0.18 \%$ & 2.47 & $0.007 * * *$ & $0.14 \%$ & 1.36 & $0.086 *$ \\
\hline EMA(10) & 757 & $0.14 \%$ & 1.93 & $0.027 * *$ & $0.10 \%$ & 0.97 & 0.165 \\
\hline EMA(20) & 740 & $0.12 \%$ & 1.63 & $0.051 *$ & $0.08 \%$ & 0.78 & 0.219 \\
\hline
\end{tabular}

$*, * *, * * *$ represent $10 \%, 5 \%, 1 \%$ significance for returns, respectively.

Long and short strategies are adopted throughout the whole period, without our trading rule.

MA families are able to generate significantly positive returns for the period HSI 14/7/95-31/8/98. 
Table 9

Nasdaq August 31, 1998 to September 9, 2002

\begin{tabular}{|c|c|c|c|c|c|c|c|}
\hline \multirow[t]{2}{*}{ Rule } & \multicolumn{7}{|c|}{ Long \& short } \\
\hline & $\mathrm{N}$ & R(long \& short) & $\mathrm{T}$ & p-value & R(long \& short)-R(bh) & $\mathrm{T}^{\prime}$ & p-value \\
\hline $\mathrm{MA}(5)$ & 1004 & $0.06 \%$ & 0.76 & 0.22 & $0.07 \%$ & 0.67 & 0.25 \\
\hline $\mathrm{MA}(10)$ & 1027 & $0.07 \%$ & 0.89 & 0.19 & $0.08 \%$ & 0.75 & 0.23 \\
\hline $\mathrm{MA}(20)$ & 989 & $0.12 \%$ & 1.58 & $0.06 *$ & $0.14 \%$ & 1.25 & 0.11 \\
\hline MA(30) & 980 & $0.14 \%$ & 1.79 & $0.04 * *$ & $0.15 \%$ & 1.40 & $0.08 * *$ \\
\hline $\mathrm{MA}(50)$ & 895 & $0.08 \%$ & 0.98 & 0.16 & $0.09 \%$ & 0.83 & 0.20 \\
\hline $\operatorname{DMA}(5,20)$ & 987 & $0.05 \%$ & 0.69 & 0.24 & $0.07 \%$ & 0.62 & 0.27 \\
\hline $\operatorname{DMA}(5,30)$ & 974 & $0.13 \%$ & 1.61 & $0.05 *$ & $0.14 \%$ & 1.27 & $0.10^{*}$ \\
\hline EMA(5) & 1002 & $0.05 \%$ & 0.66 & 0.25 & $0.06 \%$ & 0.59 & 0.28 \\
\hline EMA(10) & 991 & $0.09 \%$ & 1.20 & 0.12 & $0.11 \%$ & 0.98 & 0.16 \\
\hline EMA(20) & 996 & $0.14 \%$ & 1.78 & $0.04 * *$ & $0.15 \%$ & 1.39 & $0.08 *$ \\
\hline
\end{tabular}

${ }^{* * *} \mathrm{p}<1 \%,{ }^{* *} \mathrm{p}<5 \%,{ }^{*} \mathrm{p}<10 \%$. 
Table 10

HSI March 5, 2007 to March 31, 2009

\begin{tabular}{|c|c|c|c|c|c|c|c|}
\hline \multirow[t]{2}{*}{ Rule } & \multicolumn{7}{|l|}{ Long \& short } \\
\hline & $\mathrm{N}$ & $\mathrm{R}$ (long) & $\mathrm{T}$ & $p$-value & R(long \& short)-R(bh) & $\mathrm{T}^{\prime}$ & $\mathrm{p}$-value \\
\hline MA(5) & 494 & $0.07 \%$ & 0.60 & 0.27 & $0.17 \%$ & 2.41 & $0.008 * * *$ \\
\hline MA(10) & 494 & $0.09 \%$ & 0.73 & 0.23 & $0.19 \%$ & 2.63 & $0.004 * * *$ \\
\hline MA(20) & 467 & $0.11 \%$ & 0.89 & 0.19 & $0.21 \%$ & 2.72 & $0.003^{* * *}$ \\
\hline MA(30) & 448 & $0.22 \%$ & 1.76 & $0.04 * *$ & $0.32 \%$ & 3.97 & $<0.001 * * *$ \\
\hline MA(50) & 445 & $0.18 \%$ & 1.44 & $0.08 *$ & $0.28 \%$ & 3.44 & $<0.001 * * *$ \\
\hline $\operatorname{DMA}(5,20)$ & 464 & $0.13 \%$ & 1.07 & 0.14 & $0.23 \%$ & 3.00 & $0.001 * * *$ \\
\hline $\operatorname{DMA}(5,30)$ & 446 & $0.15 \%$ & 1.17 & 0.12 & $0.24 \%$ & 3.03 & $0.001 * * *$ \\
\hline EMA(5) & 496 & $0.10 \%$ & 0.83 & 0.20 & $0.20 \%$ & 2.81 & $0.002 * * *$ \\
\hline $\operatorname{EMA}(10)$ & 498 & $0.06 \%$ & 0.54 & 0.29 & $0.16 \%$ & 2.33 & $0.010^{* * *}$ \\
\hline EMA(20) & 497 & $0.13 \%$ & 1.10 & 0.14 & $0.23 \%$ & 3.26 & $0.001 * * *$ \\
\hline
\end{tabular}

*** $\mathrm{p}<1 \%$,** $\mathrm{p}<5 \%, * \mathrm{p}<10 \%$. 
Table 11

HSI July 14, 1995 to August 31, 1998

Wealth from TA Strategy (with $0.1 \%$ transaction costs)

\begin{tabular}{|c|c|c|c|}
\hline Rule & under trading rule & without trading rule & \\
\hline & Weatlh( $0.1 \%$ cost $)$ & Wealth( $0.1 \%$ cost $)$ & $\begin{array}{l}\text { Outperforme } \\
\text { d by }\end{array}$ \\
\hline $\mathrm{BH}$ & 0.62 & & \\
\hline MA(5) & 2.52 & 2.29 & $10.00 \%$ \\
\hline MA(10) & 2.21 & 1.99 & $10.95 \%$ \\
\hline MA(20) & 2.32 & 2.12 & $9.43 \%$ \\
\hline MA(30) & 1.67 & 1.42 & $17.69 \%$ \\
\hline MA(50) & 1.84 & 1.77 & $4.20 \%$ \\
\hline $\operatorname{DMA}(5,20)$ & 2.37 & 2.21 & $7.24 \%$ \\
\hline $\operatorname{DMA}(5,30)$ & 1.61 & 1.39 & $15.58 \%$ \\
\hline EMA(5) & 2.34 & 2.12 & $10.38 \%$ \\
\hline $\operatorname{EMA}(10)$ & 2.19 & 1.97 & $11.38 \%$ \\
\hline $\operatorname{EMA}(20)$ & 2.10 & 1.88 & $11.90 \%$ \\
\hline
\end{tabular}

A portfolio of $\$ 1 \mathrm{M}$ is set up at the beginning of the 3 periods. Transaction costs of $0.1 \%$ are considered. Under our trading rule, long and short strategy is adopted from the low point of the bull market up to the point when the stock index dropped from its peak to below the predicted stock index Pred Zt Price (refers to Figures 1-3). Thereafter, a short strategy is taken until the stock price broke the downwad trend ABC by passing through point C. Without a trading rule, long and short strategies are adopted throughout the whole period. As Tables 11 to 13 show, the bubble detection signals enable investors to generate greater wealth from $7 \%$ to $68 \%$. 
Table 12

NASDAQ August 31, 1998 to September 9, 2002

Wealth from TA Strategy (with $0.1 \%$ transaction costs)

\begin{tabular}{|c|c|c|c|}
\hline Rule & under trading rule & without trading rule & \\
\hline & Weatlh( $0.1 \%$ cost $)$ & Wealth $(0.1 \%$ cost $)$ & $\begin{array}{l}\text { Outperformed } \\
\text { by }\end{array}$ \\
\hline $\mathrm{BH}$ & 0.86 & & \\
\hline MA(5) & 1.71 & 1.07 & $60.15 \%$ \\
\hline MA(10) & 1.95 & 1.30 & $49.84 \%$ \\
\hline MA(20) & 2.48 & 2.17 & $14.27 \%$ \\
\hline MA(30) & 2.43 & 2.32 & $4.92 \%$ \\
\hline MA(50) & 2.16 & 1.77 & $22.27 \%$ \\
\hline $\operatorname{DMA}(5,20)$ & 1.93 & 1.49 & $29.68 \%$ \\
\hline $\operatorname{DMA}(5,30)$ & 2.84 & 2.48 & $14.31 \%$ \\
\hline EMA(5) & 1.70 & 1.01 & $67.90 \%$ \\
\hline EMA(10) & 2.34 & 1.61 & $45.30 \%$ \\
\hline EMA(20) & 2.78 & 2.39 & $16.42 \%$ \\
\hline
\end{tabular}


Table 13

HSI March 5, 2007 to March 31, 2009

Wealth from TA Strategy (with $0.1 \%$ transaction costs)

\begin{tabular}{|c|c|c|c|}
\hline Rule & under trading rule & without trading rule & \\
\hline & Weatlh $(0.1 \%$ cost $)$ & Wealth $(0.1 \%$ cost $)$ & $\begin{array}{l}\text { Outperformed } \\
\text { by }\end{array}$ \\
\hline $\mathrm{BH}$ & 0.24 & & \\
\hline MA(5) & 1.30 & 1.01 & $28.76 \%$ \\
\hline MA(10) & 1.76 & 1.29 & $36.29 \%$ \\
\hline MA(20) & 1.88 & 1.48 & $26.77 \%$ \\
\hline MA(30) & 2.25 & 2.08 & $8.23 \%$ \\
\hline MA(50) & 1.95 & 1.76 & $10.80 \%$ \\
\hline $\operatorname{DMA}(5,20)$ & 2.00 & 1.66 & $20.27 \%$ \\
\hline $\operatorname{DMA}(5,30)$ & 1.97 & 1.72 & $14.33 \%$ \\
\hline EMA(5) & 1.54 & 1.17 & $31.64 \%$ \\
\hline $\operatorname{EMA}(10)$ & 1.67 & 1.13 & $47.77 \%$ \\
\hline $\operatorname{EMA}(20)$ & 1.92 & 1.60 & $20.15 \%$ \\
\hline
\end{tabular}


Figure 1A

Time Series Plot of Hang Sang Index with Prediction for 1997 Bubble

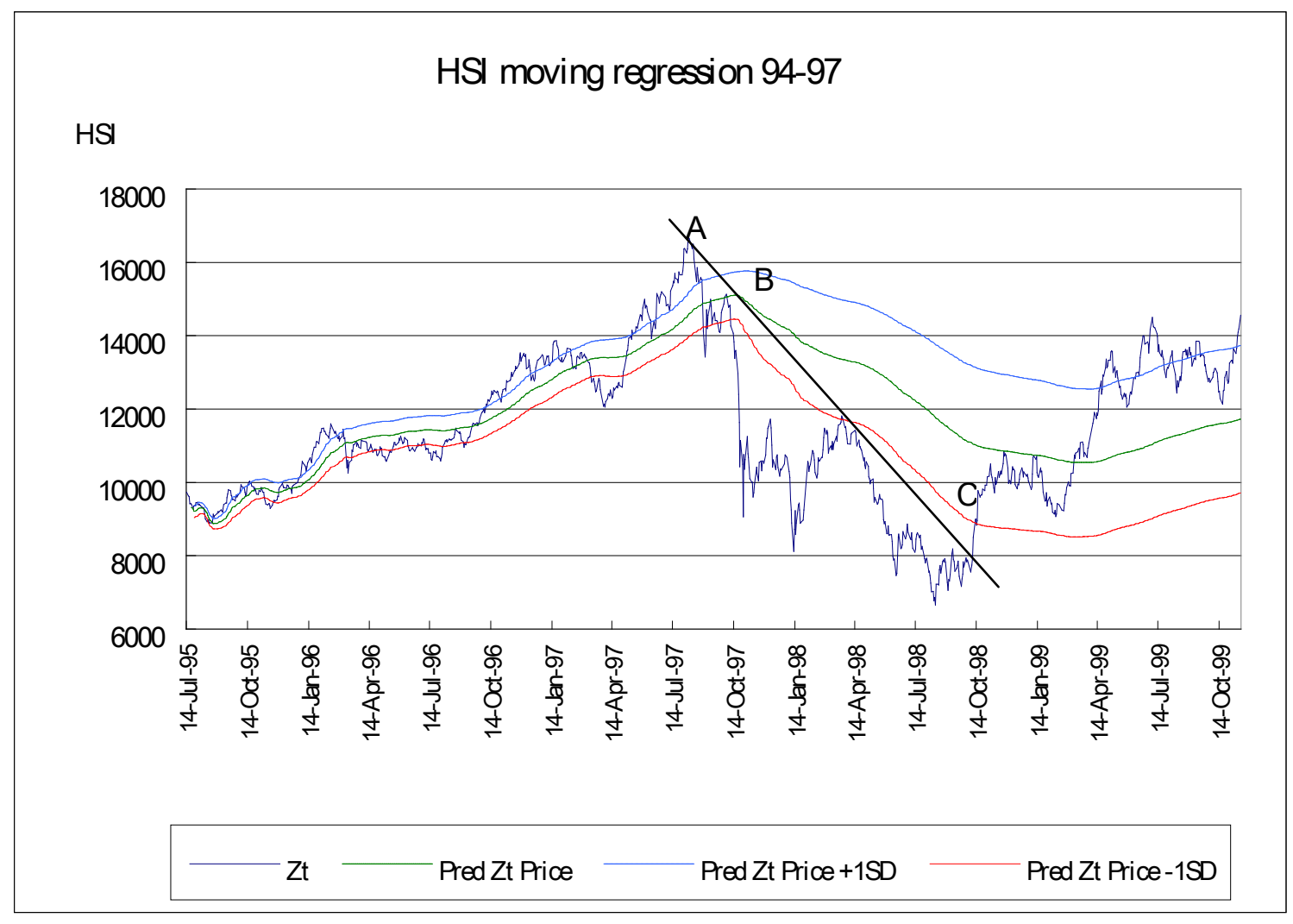


Figure 1B

Time Series Plot of Nasdaq with Prediction for dot-com Bubble

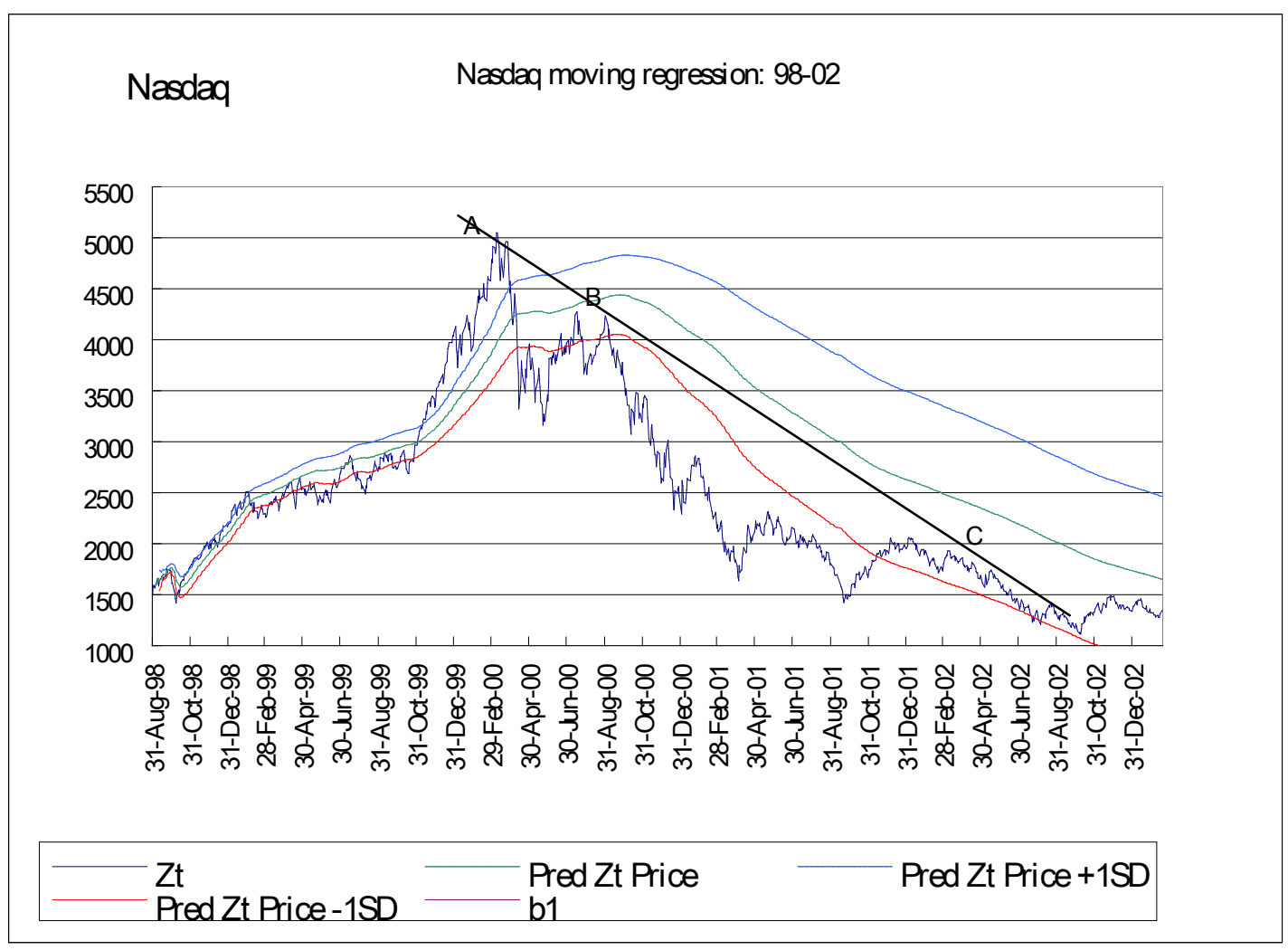


Figure 1C

Time Series Plot of Hang Seng Index with Prediction for 07 Bubble

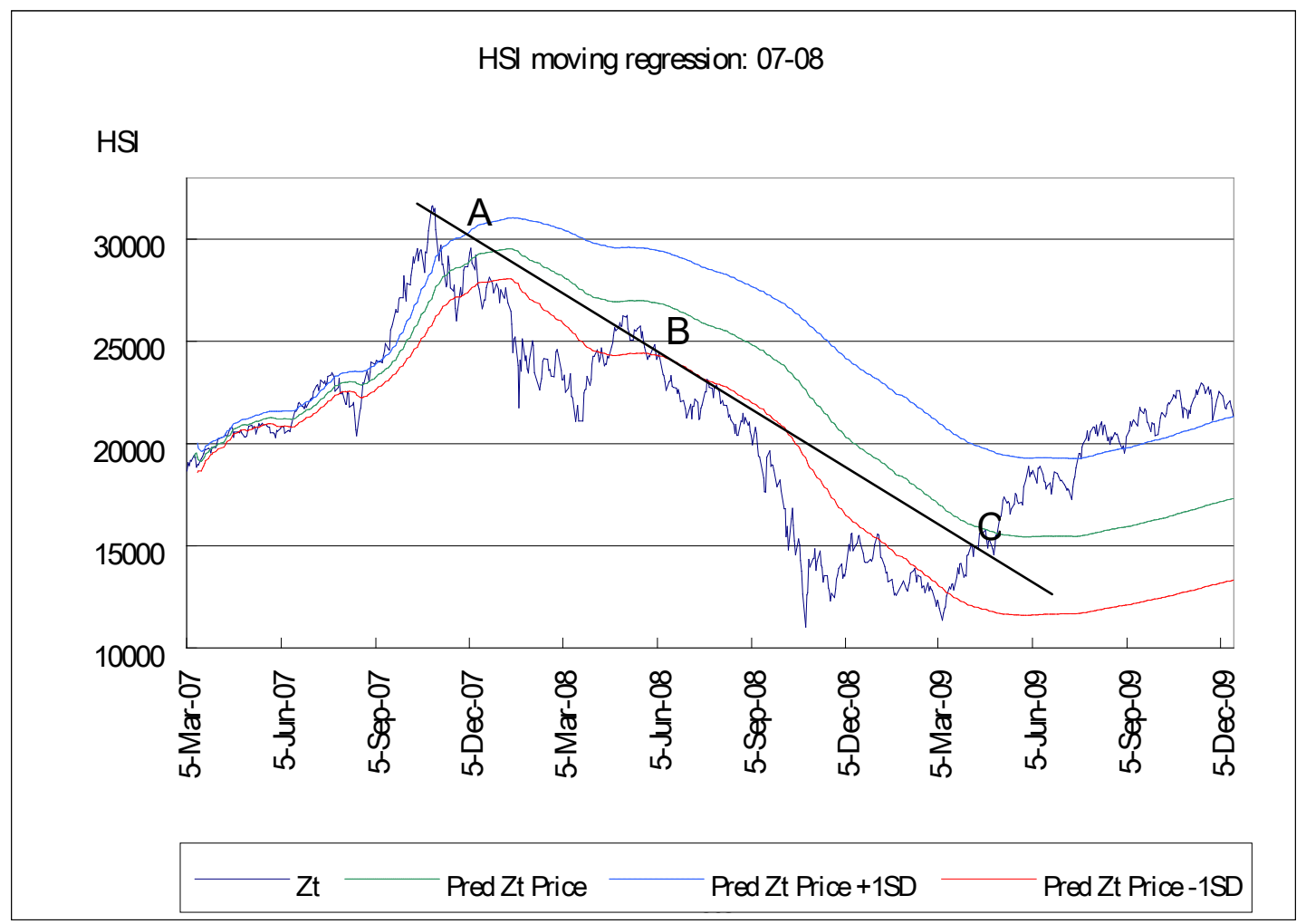

Zt denotes the stock index. Predict Zt Price is the predicted stock price from a linear regression. Pred Zt Price + 1SD/-1SD is the predicted stock price +1SD/-1SD away from the regression price. 